\title{
INFLUENCE OF FRUCTOSE ON THE MECHANISMS FOR ETHANOL- INDUCED HYPERTRIGLYCERIDAEMIA
}

\author{
I Onyesom \\ Department of Medical Biochemistry, Delta State University, \\ P. O. Box. 144, Abraka, Nigeria. \\ onyesominno@yahoo.co.uk
}

\begin{abstract}
Twelve adult albino rabbits with an average weight of $1.42 \mathrm{~kg}$ were purchased and divided equally into the normal saline, ethanol and ethanol+fructose-treated groups. The ethanol-treated group orally received $1.5 \mathrm{~g}(40 \%)$ ethanol $/ \mathrm{kg}$ body weight as single daily dose, while the ethanol + fructose-treated animals also received the same ethanol dose, but were given in addition, $0.25 \mathrm{~g}$ fructose $/ \mathrm{kg}$ body weight after about $10 \mathrm{~min}$ of the ethanol administration. The normal saline-treated rabbits were given the equivalent amount of normal saline in lieu of ethanol. The animals were exposed to these various treatments along with their usual feeding pattern for a regular period of 15 weeks. Results showed that the progressive increase $(P<0.05)$ in plasma triacylglycerol positively correlates with the changes in the activity values of an ethanol-induced microsomal enzyme, gamma- glutamyltransferase (GGT) in both ethanol and ethanol + fructosetreated animals. The relationship was stronger with the ethanol-treated group. The lipoprotein cholesterol contents showed that ethanol + fructose administration increased the amounts of cholesterol in VLDL and HDL $(P>0.05)$ but decreased $(P<0.05)$ LDL-cholesterol. These observed changes suggest that in the presence of fructose, ethanol may induce hypertriglyceridaemia by increasing hepatic secretion of VLDL and decreasing the removal of triacylglycerol from plasma.
\end{abstract}

\section{INTRODUCTION}

Except for minimal amounts produced endogenously, ethanol is essentially foreign to the body and its oxidation proceeds to the full capacity of available enzymatic systems, without efficient mechanisms for feedback regulation. Alcohol dehydrogenase (ADH), whose bulk of activity resides in the liver (Kitson \& Weiner 1996) is the enzyme involved in the metabolism of endogenous alcohols. The ADH catalized reaction is the predominant pathway for ethanol oxidation to acetaldehyde, one of the agents incriminated in the pathogenesis of mitochondrial alterations. However, the concentration of this reactive metabolite (acetaldehyde) is maintained very low, because it is readily oxidized to acetate in the mitochondria via aldehyde dehydrogenase (ALDH). Ethanol oxidation through these two successive pathways results in the transfer of hydrogen to $\mathrm{NAD}^{+}$, causing a shift in the redox potential of the liver to a more reduced level, as reflected in an increased NADH to $\mathrm{NAD}^{+}$ratio. This excess NADH produces changes in the flux of other substrates and alters the ratio of those metabolites that are dependent for reduction or oxidation on the NADH-NAD ${ }^{+}$ couple. This phenomenon has been claimed to be the hallmark for the observed ethanolinduced increase in plasma urate (Bartimaeus \& Eno-Eno 2002) and triacylglycerol (Hodge et al. 1993, Taskinen \& Nikkila, 1997).

The association between hypertriglyceridaemia and alcohol intake is well documented (Taskinen \& Nikkila 1977), and the incidence of hypertriglyceridemia varies with the population studied and this could be influenced by mode of alcohol administration, that is, whether acute (Avogaro and Cazzolato 1975) or chronic (Navder et al. 1997). Onyesom and Atakuo 
(1998) have observed that the administration of a single daily dose of 0.6 gethanol $/ \mathrm{kg}$ body weight for 6 weeks produced a steady increase in serum triacylglycerol from a basal value of $2.14 \mathrm{mmol} / \mathrm{L}$ to $2.2 \mathrm{mmol} / \mathrm{L}$ in apparently healthy normolipaemic Nigerian subjects with no history of alcohol abuse. Time-dependent changes in triacylglycerol levels have been noted during abstinence. Wallerstedt et al. (1977) found that $57 \%$ of a group of 61 male chronic alcoholics had elevated serum triacylglycerol levels $(>2.2 \mathrm{mmol} / \mathrm{L})$ on the second day of abstinence as compared with $38 \%$ on the first day.

Several documented (Clark \& Kricka 1980) mechanisms have been hypothesized to explain alcoholic hypertriglyceridaemia. Oral fructose has been demonstrated to stimulate the elimnation of ethanol from bloodstream (Berman et al. 2003; Onyesom \& Anosike 2004), but this established anti-intoxicating property has been observed to be accompanied by a further increase in serum triacylglycerol, yet the effect of fructose on the mechanisms for ethanol-induced hypertriglyceridaemia has not been investigated. This study attempts to report the influence of fructose on the biochemical evidence for microsomal induction of triacylglycerol-synthesizing enzymes, and alterations in $\mathrm{NADH} / \mathrm{NAD}^{+}$ratio and lipoprotein metabolism, which are some of the proposed mechanisms for alcoholinduced hypertriglyceridaemia.

\section{MATERIALS AND METHODS}

Animals and Feeding

Twelve adult male abino rabbits with an average initial mean weight of $1.42 \mathrm{~kg}$ were purchased from Yoha Farms, Warri, Nigeria. The rabbits were housed singly in clean metal hutches and acclimatized on growers' mash, a product of Bendel Feeds and Flour Mills (BFFM) Limited, Ewu, Nigeria for 10 days before commencing the experiment. The rabbits were then, divided into three groups with four animals each, and labeled as group $\mathrm{C}$ (control), group $\mathrm{E}$ (ethanol- treated rabbits) and group $\mathrm{F}$ (ethanol + fructose-treated rabbits). Group $\mathrm{C}$ animals took physiological saline, while the E-group animals orally received $1.5 \mathrm{~g} \quad(40 \%)$ ethanol $/ \mathrm{kg}$ body weight as single daily dose. The other group $\mathrm{F}$ rabbits also received the same ethanol dose, but were given in addition, $0.25 \mathrm{~g}$ fructose $/ \mathrm{kg}$ body weight after about $10 \mathrm{~min}$ of the ethanol dose. Syringes were used to dispense the appropriate preparations and amounts into the mouth of the animals.

The animals were exposed to these treatments along with their usual feeding pattern: about $80 \mathrm{~g}$ wet weight of feed $/ \mathrm{kg}$ body weight/day, for a continuous period of 15 weeks. The feeds were mixed with water in a ratio of 10:1 (w/v) so as to achieve a texture acceptable to the animals, and the stale feed remnants were regularly discarded. The animals were allowed to drink water $a d$ libitum.

\section{Collection of Blood Sample}

Whole blood was collected from each rabbit by puncturing the vein in the right ear with 21 -guage hypodermic needles, after the $5^{\text {th }}$, $10^{\text {th }}$ and $15^{\text {th }}$ week of treatment, into lithium heparinized tubes. The blood samples were then centrifuged at $1,200 \mathrm{x} \mathrm{g}$ for $5 \mathrm{~min}$ at room temperature to separate the plasma samples which were stored refrigerated and analysed within $48 \mathrm{hr}$.

\section{Sample Analyses}

Plasma urate was estimated by the uricaseaminoantipyrine method (Caraway 1963), but the plasma triacylglycerol level was colorimetrically quantified by the end-point colorimetric method (Searcy 1969), while the activity value of plasma gammaglutamyl transferase (GGT) was determined by the colorimetric method (Szasz 1969). Plasma VLDL- and LDL-cholesterol were estimated by formulae (Friedwald et al. 1972), whereas, plasma HDL-cholesterol was determined by colorimetric method (Burstein \& Mortin 1969). 


\section{Statistics}

Analysis of variance (ANOVA) was used to compare the data, and a post-hoc test was performed using the Tukey-Kramer Multiple Comparisons Test. The level of statistical significance was established at the 5\% probability level.

\section{RESULTS}

The data obtained are shown in Figures 1-3, and Table 1. Fig. 1 shows that alcohol consumption progressively increased plasma urate to a significant $(\mathrm{P}<0.05)$ level at the $15^{\text {th }}$ week of administration when compared with the values induced by either ethanol + fructose (F) or normal saline (C) administration. The differences between the group $\mathrm{C}$ and $\mathrm{F}$ plasma urate did not differ significantly $(\mathrm{P}>0.05)$, although at the end of the exposure period, the group $\mathrm{F}$ value was observed to be $10 \%$ higher than the $\mathrm{C}$ value.

Table 1: Changes in lipoproteins induced by the administration of normal saline ${ }^{\mathrm{a}}$, ethanol $^{\mathrm{b}}$ and ethanol + fructose $^{c}$ in rabbits.

\begin{tabular}{cccc}
\hline \multirow{2}{*}{$\begin{array}{c}\text { Treatment Duration } \\
\text { (wk) }\end{array}$} & \multicolumn{3}{c}{ Change in lipoprotein-cholesterol levels (mmol/L) } \\
\cline { 2 - 4 } VLDL & HDL & LDL \\
\hline 0 & & & \\
(Basal values) & $0.273 \pm 0.018$ & $0.875 \pm 0.070$ & $1.205 \pm 0.034$ \\
& & & \\
5 & $0.246 \pm 0.016^{\mathrm{a}}$ & $0.760 \pm 0.080^{\mathrm{a}}$ & $1.095 \pm 0.160^{\mathrm{a}}$ \\
& $0.300 \pm 0.020^{\mathrm{b}}$ & $0.980 \pm 0.160^{\mathrm{b}}$ & $1.275 \pm 0.124^{\mathrm{b}}$ \\
& $0.325 \pm 0.016^{\mathrm{c}}$ & $0.940 \pm 0.144^{\mathrm{c}}$ & $1.335 \pm 0.116^{\mathrm{c}}$ \\
& & & \\
& & & \\
& $0.205 \pm 0.028^{\mathrm{a}}$ & $0.820 \pm 0.100^{\mathrm{a}}$ & $1.275 \pm 0.150^{\mathrm{a}}$ \\
& $0.352 \pm 0.014^{\mathrm{b}}$ & $1.130 \pm 0.092^{\mathrm{b}}$ & $1.218 \pm 0.160^{\mathrm{b}}$ \\
& $0.341 \pm 0.010^{\mathrm{c}}$ & $1.200 \pm 0.132^{\mathrm{c}}$ & $0.779 \pm 0.072^{\mathrm{c}}$ \\
& & & \\
& & & \\
& $0.245 \pm 0.016^{\mathrm{a}}$ & $0.800 \pm 0.060^{\mathrm{a}}$ & $1.155 \pm 0.124^{\mathrm{a}}$ \\
& $0.364 \pm 0.020^{\mathrm{b}}$ & $1.180 \pm 0.064^{\mathrm{b}}$ & $1.166 \pm 0.144^{\mathrm{b}}$ \\
& $0.368 \pm 0.022^{\mathrm{c}}$ & $1.250 \pm 0.092^{\mathrm{c}}$ & $0.522 \pm 0.048^{\mathrm{c}}$ \\
\hline
\end{tabular}

Values are expressed as mean \pm SD for four rabbits per group.

The plasma TAG rapidly increased in both ethanol and ethanol + fructose-treated animals. The changes became significant at the $5 \%$ probability level when compared with the control (normal saline-treated group) values at the end of the 15-week period. The trend could be troubling, considering the implications of hypertriglyceridemia (Fig. 2). 


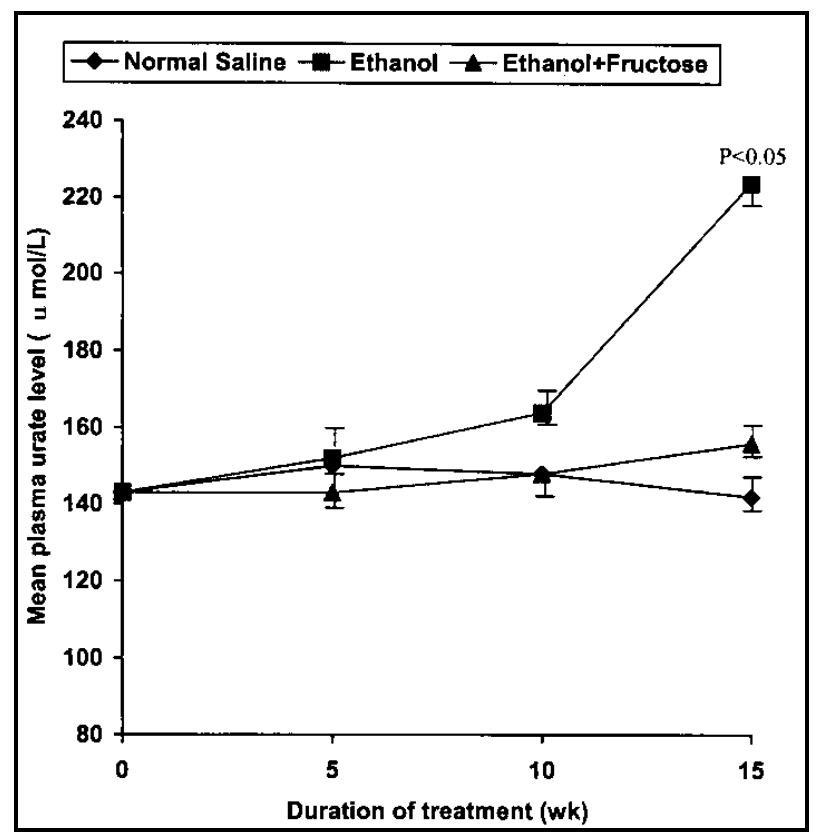

Figure 1: Changes in mean plasma urate level for the normal saline, ethanol and ethanol + fructose treated rabbits.

No. of determinations $=2 \mathrm{n}$; and $\mathrm{n}=4$ rabbits for each group

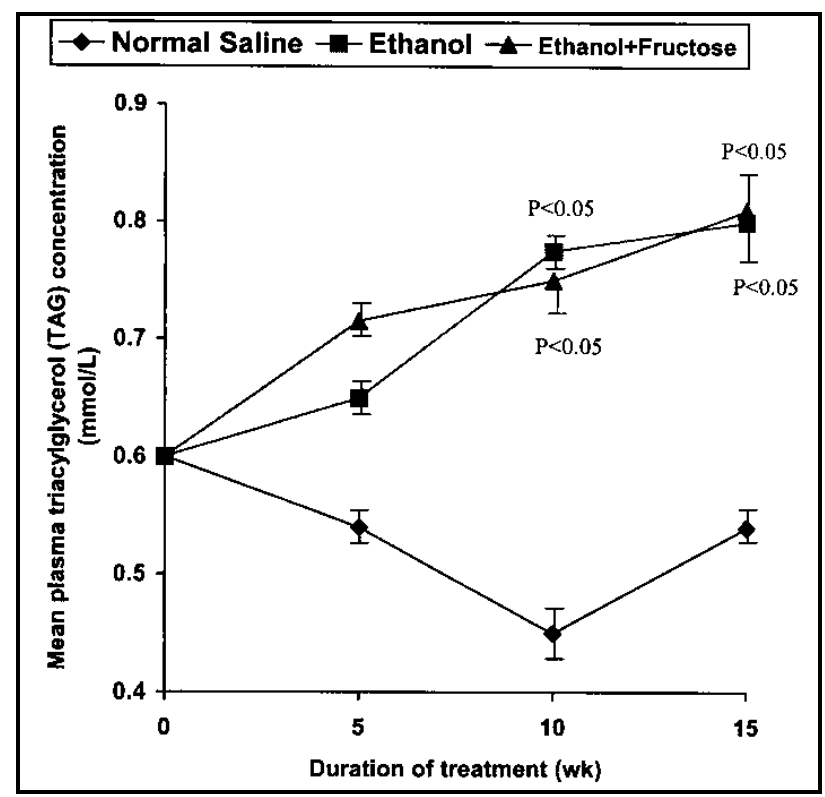

Figure 2: Changes in mean plasma triacylglycerol concentrations following normal saline, ethanol and ethanol + fructose treatments.

No. of determinations $=2 n$; and $n=4$ rabbits for each group 


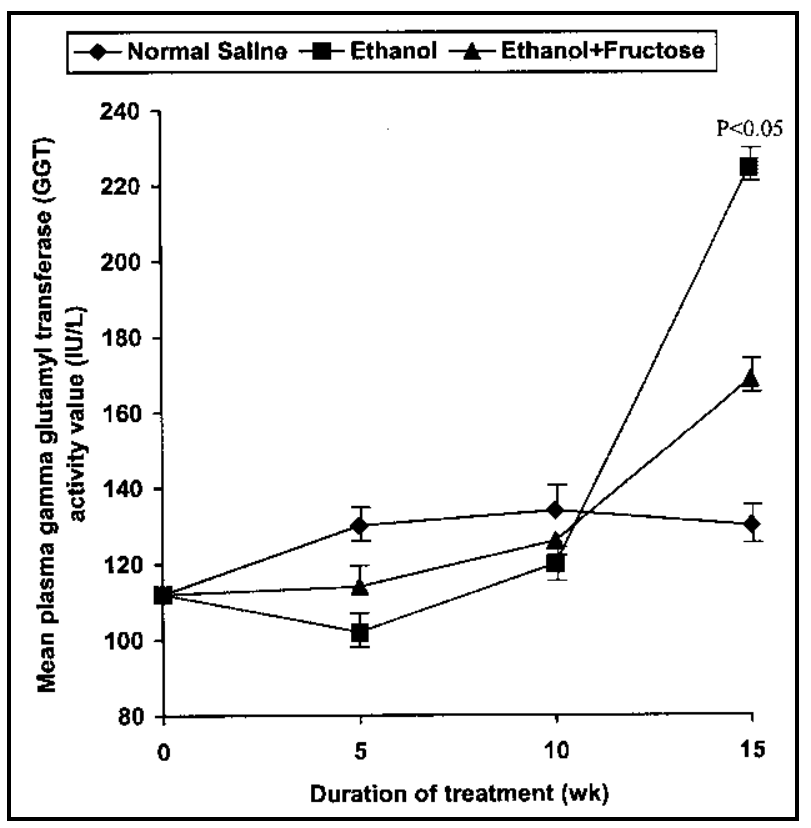

Figure 3: Changes in mean plasma gamma glutamyl transferase (GGT) activity values induced by normal saline, ethanol and ethanol + fructose treatments.

No. of determinations $=2 \mathrm{n}$; and $\mathrm{n}=4$ rabbits for each group

Changes in GGT activity values, a microsomal enzyme, indicate that chronic administration of ethanol and ethanol + fructose significantly $(\mathrm{P}<0.05)$ increased gamma-glutamyl transferase (GGT) activity value when compared with the control and basal values. (Fig. 3). This observation is linked to the fact that ethanol oxidation is also catalyzed by a specific microsomal cytochrome (P4502E1), and this complement pathway increases in activity after prolonged consumption (Lieber \& Decarli 1970). Thus, chronic ethanol feeding results in proliferation of the smooth endoplasmic reticulum, which in turn secretes GGT, hence the marked increase in its plasma activity. The GGT activity values (Fig. 3) positively correlates with the changes in plasma TAG (Fig. 2) suggesting that ethanol-induced microsomal function may contribute to the increase in plasma TAG.
Changes in lipoproteins (Table 1) show that ethanol and ethanol + fructose administration rapidly increased the lever (secretion) of VLDL-, LDL- and HDLcholesterol but ethanol + fructose-treatment reduced the LDL level. The changes in HDL- and LDL- cholesterol at the end of the 15-week exposure period for both experimental groups differ significantly $(\mathrm{P}<0.05)$ when compared with basal values.

\section{DISCUSSION}

Metabolism of ethanol generates NADH + $\mathrm{H}^{+}$which have been observed to produce important metabolic consequences in the body. The excess $\mathrm{H}^{+}$so formed, stimulates fatty acid synthesis. The fatty acids are first activated by incorporation of carnitine into the molecular structure, after which they are introduced into the mitochondrial matrix by a transferase mechanism and subsequently oxidized. But ethanol impairs the activity of carnitine transferase (Parker et al. 1974) and 
this reduces beta-oxidation. The increased level of NADH raises the concentration of glycerol-3-phosphate which esterifies the fatty acids, resulting in triacylglycerol synthesis, and possibly its hepatic accummulation. Ethanol-induced increase in $\mathrm{NADH}$ also causes an elevation in [lactate]/[pyruvate] ratio (Mascord et al. 1991) and this leads to hyperlactacidaemia, an acidotic condition that decreases the capacity of the kidneys to excrete uric acid (Vamvakas et al. 1998), and possibly causing hyperuricemia.

Fructose has been reported to accelerate blood alcohol clearance rate by re-oxidising $\mathrm{NADH}$ to $\mathrm{NAD}^{+}$needed for further alcohol oxidation (Scholz \& Nohl 1976, Mascord et al 1991) and so, minimizes the increase in $\mathrm{NADH} / \mathrm{NAD}^{+}$redox ratio induced by alcohol. This tendency ameliorates the metabolic disorders associated with the redox change. Hyperuricemia is one of such established secondary metabolic consequences as supported by this investigation (Fig. 1). The same figure also confirms that the use of oral fructose possesses the benefit of reducing the incidence of alcoholic hyperuricemia, since the percentage increase in plasma urate in the presence of fructose did not differ significantly from the control values. It follows that dangerous elevation in plasma urate may not accompany the use of oral fructose as an amethystic agent.

However, the supposed maintenance of the NADH-NAD ${ }^{+}$change by fructose did not restore the attendant effect on plasma TAG (Fig. 2). Similarly, methylene blue which attenuated the NADH/NAD ${ }^{+}$redox increase produced by ethanol, did not prevent the development of alcoholic fatty liver in rats (Ryle et al. 1985). These observations therefore, demand alternative mechanism(s) to explain the increase in plasma TAG of (hypertriglyceridaemic).

The finding of a positive correlation between serum GGT activities and serum TAG levels in a group of 109 patients submitted for routine lipid and lipoprotein screening has pointed to the possibility that the elevated TAG levels may be due to microsomal enzyme induction of enzymes involved in hepatic TAG production (Martin et al. 1975).

Alcohol-fed rats showed no changes in the activity of enzymes for de novo fatty acid synthesis (Tijburg et al. 1988) but the availability of fatty acids is markedly enhanced by the impairment of mitochondrial $\beta$-oxidation by alcohol (Martin et al 1975). Increased levels of fatty acids has been reported to elicit the hepatic secretion of fatty acid-binding protein (LFABPc), which normally transports fatty acids in the cytosol, binds to microsomes and exerts a direct stimulatory effect on triacylglycerol-synthesizing enzymes (Day et al 1993; Gossett et al 1996). Available evidence from the correlation between plasma GGT activity values (Fig. 3) and the changes in plasma TAG (Fig. 2) possibly indicates a minor level in the induction of microsomal enzymes involved in hepatic TAG production.

Table 1, shows that ethanol + fructose consumption increased plasma VLDL- and HDL- but decreased LDL- components. These data suggest that in the presence of fructose, ethanol may produce accelerated clearance of LDL, decreased conversion of VLDL to LDL or increased hepatic synthesis of VLDL. The formation of LDLacetaldehyde adducts in vitro increased the catabolism of this lipoprotein in humans (Kesaniemi et al 1987). The in vivo presence of such adducts has been demonstrated in actively drinking alcoholics (Wehr et al 1993), and were particularly abundant in VLDL, less in LDL, and non-detectable in HDL, suggesting that the acetaldehydeinduced modification of LDL, apoB occurs in the liver prior to the excretion of VLDL.

Chait et al (1972) found that alcohol did not decrease peripheral uptake of TAG from 
plasma. They suggested that ethanol causes an increased hepatic secretion of lipoproteins (especially VLDL). This has been observed to induce hypertriglyceridaemia in individuals predisposed by having a low ability to clear TAG from plasma. Onyesom and Anosike (2005) have reported that ethanol + fructose administration further increased plasma TAG levels in rabbits. They observed that there was no such proportionate increase in the liver, suggesting that ethanol in the presence of fructose may decrease peripheral uptake of TAG from plasma and induce hypertriglyceridaemia.

In the presence of fructose, ethanol may induce hypertriglyceridaemia by possibly decreasing the removal of TAG from plasma and increasing the secretion of VLDL which may contain acetaldelyde-adducts. The development of fructose in the management of alcohol intoxication and elated problems should recognize the identified effects of fructose on the mechanisms for ethanolinduced hypertriglyceridaemia.

\section{REFERENCES}

Avogaro P and Cazzolato G 1975 Changes in the composition and physicochemical characteristics of serum lipoproteins during ethanol-induced lipemia in alcoholic subjects. Metabolism 24:12311242.

Bartimaeus ES and Eno-Eno M 2002 The effect of alcohol on uric acid level in consumers. J. Appl. Sci. Environ. Mgt. 6(1):5-7.

Berman PAM, Baumgarten I and Viljoen DL 2003 Effect of oral fructose on ethanol elimination from the bloodstream. South Afr. J. Science. 99 (Jan/Feb): 47-50.

Burstein M and Mortin R 1969 Quantitative determination of HDL- cholesterol using the enzymatic- colorimetric method. Life Sci. 8:345-347.

Caraway WT 1963 Quantitative determination of uric acid. Clin. Chem. 4:239-243.
Chait A, Mancini M, February AW and Lewis B 1972 Clinical and metabolic study of alcoholic hypelipidaemia. Lancet ii: 62-64.

Clark PMS and Kricka LJ 1980 Medical Consequences of Alcohol Abuse. Ellis Horwood Ltd., Chichester, England.

Day CP, James OFW and Brown ASM 1993 The activity of the metabolic form of hepatic phosphatidate phosphohydrolase correlates with the severity of alcoholic fatty liver in human beings. Hepatology 18:832-838.

Friedwald WT, Levy RI and Fredrickson DS 1972 Estimation of VLDL- and LDLcholesterol. Clin. Chem. 18:499-502.

Gossett RE, Frolov AA and Roths JB 1996 Acyl-CoA binding proteins: Multiplicity and function. Lipids 31:895-918.

Hodge AM, Dowse GK, Collins VR and Zimmet PZ 1993 Abnormal glucose tolerance and alcohol consumption in three population at high risk of noninsulin dependent diabetes melliitus. Am. J. Epidemiol. 137(2):178-189.

Kesaniemi YA, Kervinen K and Miettinen TA 1987 Acetaldehyde modification of low density lipoprotein accelerates its catabolism in man. Eur. J. Clin. Invest. 17:29-36.

Kitson KE and Weiner H 1996 Ethanol and acetaldehyde metabolism: Past, present and future. Alcohol. Clin. Exp. Res. 20:82A-92A.

Lieber CS and DeCarli LM 1970 Hepatic microsomal ethanol oxidising system: In vitro characteristics and adaptive properties in vivo. J. Biol. Chem. 245:2505-2512.

Martin PJ, Martin JV and Goldberg PM 1975 Gamma-glutamyl transferase, triglycerides and enzyme induction. Lancet $\mathbf{I}: 17-18$.

Mascord D, Smith J, Starmer GA and Whitfield JB 1991 The effect of fructose on alcohol metabolism and the (lactate)/(pyruvate) ratio in man. Alcohol. Alcohol. 26:53-59.

Navder KP, Baraona E and Lieber CS 1997 Restoration of ethanol-induced 
mitochondrial dysfunction by polyenylphosphatidylcholine (PPC) in rats. FASEB J. 11:A383.

Onyesom I and Anosike EO 2004 Oral fructose-induced changes in blood ethanol oxidokinetic data among healthy Nigerian. Southeast Asian J. Trop Med Publ Health 35 (2): 476-480.

Onyesom I and Anosike EO 2005 Effect of oral fructose on ethanol-induced changes in plasma and hepatic lipids. Acta Medica et Biologica 53 (2):33-36.

Onyesom I and Atakuo EO 1998 An investigation into relationship between alcohol-induced changes in serum triacylghycerol and blood pressure. Nigerian J. Biochem Mol Biol. 13:7983.

Parker SL, Thomson JA and reitz RC 1974 Effects of chronic ethanol ingestion upon acyl-CoA:Carnitine acyltransferase in liver and heart. Lipids 9:520-524

Ryle PR, Chakraborty J and Thomson AD 1985 The effect of methylene blue on the hepatocellular redox state and liver lipid content during chronic ethanol feeding in the rat. Biochem. J. 232:877-882.

Scholz R and Nohl H 1976 Mechanism of the stimulatory effect of fructose on ethanol oxidation in perfused rat liver. Eur. J. Biochem. 63:449-458.
Searcy RL 1969 Diagnostic Biochemistry. McGraw Hill, New York.

Szasz G 1969 Colorimetric determination of gamma-glutamyl transferase activity. Clin. Chem. 22:124-136.

Taskinen MR and Nikkila EA 1997 Nocturnal hypertriglyceridemia and hyperinsulinemia following moderate evening intake of alcohol. Acta Med. Scand. 202:173-177.

Tijburg LBM, Maquedano A and Bijleveld C 1978 Effects of ethanol feeding on hepatic lipid synthesis. Arch. Biochem. Biophys. 267:568-579.

Vamvakas S, Teschner M, Bahner U and Heidland A 1998 Alcohol abuse: potential role in electrolyte disturbances and kidney disease. Clin Nephrology 49 (4): 205-213.

Wallerstedt S, Gustafson A and Olsson R 1977 Serum lipids and lipoproteins during abstinence after heavy alcohol cnsumption. Scandinavian Clin Lab Invest. 37:599-604.

Wehr H, Rodo M, Lieber CS and Baraona E 1993 Acetaldehyde adducts and autoantibodies against VLDL and LDL in alcoholics. J. Lipid Res. 34:12371244. 